\title{
Evaluation of post sterilization ectopic gestations
}

\section{Lavanya K. Sarella*}

Department of Obstetrics and Gynecology, Rangaraya Medical College, Kakinada, Andhra Pradesh, India

Received: 02 February 2017

Accepted: 04 March 2017

\section{*Correspondence:}

Dr. Lavanya K. Sarella,

E-mail: lavanyakumarisarella@yahoo.com

Copyright: (C) the author(s), publisher and licensee Medip Academy. This is an open-access article distributed under the terms of the Creative Commons Attribution Non-Commercial License, which permits unrestricted non-commercial use, distribution, and reproduction in any medium, provided the original work is properly cited.

\section{ABSTRACT}

Background: Tubal sterilization is considered a permanent method of contraception. The risk of failure of tubectomy is only $0.1-0.3 \%$. Most often the pregnancy following tubal sterilization is ectopic gestation.

Methods: 35 cases of post sterilization ectopic gestation were evaluated during a period of January 2014 to December 2015 at Government General Hospital, Rangaraya Medical College, Kakinada, Andhra Pradesh, India.

Results: Number of post sterilization ectopic gestation were $(n=35) 33 \%$, in 105 ectopic gestations during this period. 93\% were in the age group of 20-30years with a mean age of $30.5 y$ years. $82 \%$ were gravida three who underwent sterilization with two living children. $62 \%$ of women presented with 4-6 weeks of amenorrhoea. $97.14 \%$ underwent minilaparotomy and out of which $74 \%$ were performed in Government hospitals. Puerperal sterilizations constituted $85 \%$. In all cases ectopic gestation occurred within 10years of undergoing sterilization and all cases presented with hemoperitoneum. Site of rupture is ampulla in $31.4 \%$ of cases. Length of remaining tube is $7-8 \mathrm{~cm}$ in $60 \%$ of cases.

Conclusions: History of tubal sterilization does not rule out the possibility of ectopic gestation even when many years after the tubectomy. Adopting correct technique can reduce the failure rates. Woman should be counselled about the possibility of intra and extra uterine gestation at the time of performing tubectomy.

Keywords: Contraception, Ectopic gestation, Mini laparotomy, Modified Pomeroy’s method

\section{INTRODUCTION}

Tubal sterilization is considered highly effective method of preventing conception. Ectopic pregnancy continues to be an important cause of maternal death. ${ }^{1}$

The incidence of pregnancy after sterilization is relatively small but tubal ectopic pregnancy in such cases is significant. $^{2}$ Contraceptive failure has been considered one of the important factors associated with this increased ectopic pregnancy incidence. ${ }^{3}$

Post sterilization ectopic gestations are beginning to account for more than $10 \%$ of all ectopic gestations. ${ }^{1,4,5}$ Still the absolute risk of developing post sterilization ectopic gestation is lesser than observed for normal women.

\section{METHODS}

This study was conducted in the Department of Obstetrics and Gynecology, Government General Hospital, Rangaraya Medical College, Kakinada, Andhra Pradesh, India during the period of January 2014 to December 2015. 35 cases of ectopic gestation following tubectomy were included after taking written informed consent for participation.

A detailed evaluation of these cases regarding age, interval between tubal sterilization and ectopic gestation, type of tubal ligation, intraoperative features like site of rupture, remaining length of tube after tubectomy, the side of the tube affected, place and time of tubectomy, whether sterilization has been done as interval procedure or along with medical termination of pregnancy or cesarean section or in puerperium were noted. We 
classified pregnancies as postpartum tubal sterilization (performed at same time of cesarean section or after vaginal delivery) and interval sterilization (performed in women who had not recently been pregnant).

\section{RESULTS}

The total number of ectopic gestations during this period were 105. Post sterilization ectopic gestations incidence is $33 \%(n=35)$.

Table 1: Age and gravida $(\mathrm{n}=35)$.

\begin{tabular}{|llll|}
\hline Age & $20-30$ years & 28 & $80 \%$ \\
\hline & $31-40$ years & 6 & $17.14 \%$ \\
\hline & $>40$ years & 1 & $2.8 \%$ \\
\hline Gravida & 3 & 29 & $82.8 \%$ \\
\hline & 4 & 4 & $11.4 \%$ \\
\hline & 5 & 2 & $5.71 \%$ \\
\hline
\end{tabular}

Of the total of 35 cases $28(80 \%)$ women were in the age group or 20-30 years with a mean age of 30.5 years. 29 $(82 \%)$ women are gravida three who underwent tubectomy with two living children.

Table 2: Period of amenorrhoea $(n=35)$.

\begin{tabular}{|lll|}
\hline No H/O amenorrhoea & 2 & $5.71 \%$ \\
\hline$<3$ weeks & 5 & $14.2 \%$ \\
\hline 4-6 weeks & 22 & $62.8 \%$ \\
\hline 6-8weeks & 6 & $17.14 \%$ \\
\hline
\end{tabular}

Period of amenorrhoea by the time ectopic gestation was diagnosed ranged from 4 to 6weeks in, with $22(62.8 \%)$. Two patients presented without amenorrhoea but menstrual history revealed spotting and hypomenorrhoea in the previous cycle.

\section{History of sterilization $(n=35)$}

Table 3: Place of sterilization $(n=35)$.

\begin{tabular}{|lll|}
\hline Primary health center & 22 & $\mathbf{6 2 . 8 \%}$ \\
\hline Tertiary institute & 4 & $11.4 \%$ \\
\hline Private hospital & 9 & $25.71 \%$ \\
\hline
\end{tabular}

Table 4: Type of sterilization.

\begin{tabular}{|lll|}
\hline Minilaparotmy & 34 & $97.14 \%$ \\
\hline Lap rings & 1 & $2.8 \%$ \\
\hline
\end{tabular}

Table 5: Time of sterilization.

\begin{tabular}{|llll|}
\hline Puerperal & $<1$ week & 11 & $31.42 \%$ \\
\hline & $1-4$ weeks & 14 & $40 \%$ \\
\hline & During LSCS & 5 & $14.2 \%$ \\
\hline Interval & & 5 & $14.2 \%$ \\
\hline
\end{tabular}

Table 6: Interval between sterilization and ectopic gestation.

\begin{tabular}{|lll|}
\hline$<1$ year & 1 & $2.8 \%$ \\
\hline $1-2$ years & 9 & $25.71 \%$ \\
\hline $2-5$ years & 14 & $40 \%$ \\
\hline $5-10$ years & 6 & $17.14 \%$ \\
\hline$>10$ years & 5 & $14.2 \%$ \\
\hline
\end{tabular}

As per place of tubectomy most of the sterilizations $(26=74 \%)$ occurred in Government hospitals ranging from primary health center to tertiary institute. Type or sterilization procedure in 34 cases $(97.14 \%)$ was done by minilaparotomy. As per the time of tubectomy is regarded $30(85.71 \%)$ are puerperal sterilizations, 25 cases $(71.4 \%)$ were after vaginal delivery with time period ranging from 1-4 weeks. 5 (14.28\%) cases were done during cesarean section. Interval between tubectomy and ectopic gestation ranged from 1 to 10years in 30 cases $(85.7 \%)$.

\section{Intraoperative findings $(n=35)$}

Table 7: Site of tubectomy.

\begin{tabular}{|lll|}
\hline Isthmus & 11 & $31.42 \%$ \\
\hline Ampulla & 23 & $65.71 \%$ \\
\hline Not done on one side & 1 & $2.8 \%$ \\
\hline
\end{tabular}

Table 8: Site of rupture.

\begin{tabular}{|lll|}
\hline Isthmus & 4 & $11.4 \%$ \\
\hline Ampulla & 18 & $51.42 \%$ \\
\hline Tubal abortion & 11 & $31.42 \%$ \\
\hline Ovary & 1 & $2.8 \%$ \\
\hline Corneal & 1 & $2.8 \%$ \\
\hline
\end{tabular}

Table 9: Length of affected fallopian tube.

\begin{tabular}{|lll|}
\hline$<5 \mathrm{~cm}$ & 2 & $5.71 \%$ \\
\hline $5-6 \mathrm{~cm}$ & 11 & $31.42 \%$ \\
\hline $7-8 \mathrm{~cm}$ & 21 & $60 \%$ \\
\hline Scar not found on tube & 1 & $2.8 \%$ \\
\hline
\end{tabular}

In $23(65.71 \%)$ cases site of tubectomy was found to be ampulla and in one case tubectomy was found to be not performed on one tube due to adhesions. Ectopic gestation occurred in the tube on which tubectomy was done.

All cases presented with rupture. Site of rupture is ampulla in $18(51.42 \%)$. Tubal abortion was reported in $11(31.4 \%)$ cases. Ovarian and corneal pregnancy is reported one in each case.

Length of tube is $7-8 \mathrm{~cm}$ in $21(60 \%)$ cases, and $<5 \mathrm{~cm}$ in $2(5.7 \%)$ cases. Affected tube on right side in $22(62.8 \%)$ cases. 


\section{DISCUSSION}

The incidence of failure of voluntary sterilization is rare about $0.13-1.3 \%$ of which ectopic gestation constitutes about $15-33 \% .{ }^{6}$ Chances of failure are more in younger age as almost $80 \%$ failure were <30years which correlates with previous study of Trussel et al and Peterson et al. ${ }^{7,8}$ Failure interval was between 1 and 10 years in $85.71 \%$ of patients which coincides with Vessey et al. and Lassner et al. ${ }^{9,10}$ Evaluation of previous surgery was evaluated $62.8 \%$ cases were from PHC. This could be explained with Hughes, Roy et al. and Stovall et al. studies ${ }^{11-13}$ mentioning that proper training is necessary to reduce the sterilization failures. Guidelines are given in standards for female sterilization services, Ministry of Health and Family Welfare, Government of India, in 2006 October states, The operating surgeon should identify each fallopian tube clearly, tracing right up to fimbria. Excision of $1 \mathrm{~cm}$ of fallopian tube should be done. The site of the occlusion of tube must be in isthmic portion 2-3 cm away from uterine cornu. The risk of ectopic gestation depends on type of tubal sterilization. Among women who undergo tubal ligation, the risk is about $1 / 7$ the expected risk had they continued their previous contraception. ${ }^{14}$

The probable explanation for ectopic gestation after tubal ligation is recanalization or formation of tubo-peritoneal fistula. Sperm may pass through, but the fertilized ovum cannot, so implantation occurs classically in the distal tubal segment ${ }^{4,15}$ In the process of recanalization there is an abnormal reconstitution of the tubal lumen with the formation of blind pouch and slit like spaces and that is responsible for greater likelihood of ectopic gestation. ${ }^{16}$ Rock et al suggested that the development of tubo peritoneal fistula subsequent to sterilization was associated with development of endometriosis especially when ligation site was within $4 \mathrm{~cm}$ of the cornua. However the high risk of ectopic gestation following contraceptive failure in women who undergo tubal sterilization may be caused by the altered structure of the fallopian tube and impaired embryo-tubal transport. ${ }^{17}$

The incidence of ectopic after sterilization is higher when it is performed during postpartum period because the edematous, friable and congested fallopian tubes following pregnancy increase the chances of incomplete occlusion of the tubal lumen. ${ }^{18}$ The physicians should raise a suspicion for ectopic gestation when they encounter signs of pregnancy in a woman who has undergone sterilization especially if two or more years have elapsed since sterilization. ${ }^{19}$ Woman's age at the time of tubal sterilization affected the likelihood of failure of the procedure which in turn affects the likelihood of ectopic pregnancy. ${ }^{20}$ In our study we found that the woman who were under 30 at the time of tubectomy were $93 \%$. The primary effect of age on the risk of ectopic pregnancy is its effect on fecundity. ${ }^{21}$ Procedural technique is probably a critical determinant of the risk of sterilization failure. ${ }^{22,23}$ Ampulla is the most common site of ectopic pregnancy. ${ }^{24}$ In $97.14 \%$ of the cases tubal sterilization is done with Pomeroy or Modified Pomeroy's technique which have a failure rate of $1-4 / 1000$ cases.

\section{CONCLUSION}

Whenever tubal sterilization is to be performed in conjunction with a pregnancy event such as MTP or puerperium meticulous technique is required to avoid failure. Sterilization should be done in follicular phase of cycle. It is much more important that the woman undergoing sterilization must be counselled for the possibility and the risk of both intra and extra uterine gestation subsequent to the sterilization.

Funding: No funding sources

Conflict of interest: None declared

Ethical approval: The study was approved by the Institutional Ethics Committee

\section{REFERENCES}

1. Brenner PF, Benedetti T, Mishell DR. Ectopic pregnancy following tubal sterilization surgery. Obstet Gynecol. 1977;49;323-4.

2. Thelin TJ, Nagell JR. Ruptured ectopic pregnancy after bilateral tubal ligation. Obstet Gynecol. 1972;39:589-90.

3. Rana P, Kazmi I, Singh R, Afzal M, Al-Abbasi FA. Ectopic pregnancy: a review. Arch Gynecol Obstet. 2013;288:747-57.

4. Davis MR, Recurrent ectopic pregnancy after tubal sterilization. Obstet Gynaecol. 1986:68:44-5.

5. Wolf GC, Thompson NJ. Female sterilization and subsequent ectopic pregnancy. Obstet Gynecol. 1980;55:17-9.

6. Awonuga AO, Imudia AN, Shavell VI. Failed female sterilization: a review of pathogenesis and subsequent contraceptive options. J Reprod Med. 2009;54(9):541-54.

7. Trussell J, Guilbert E, Hedley A. Sterilization failure, sterilization reversal, and pregnancy after sterilization reversal in Quebec. Obstet Gynecol. 2003;101:677-84.

8. Peterson HB, Xia Z, Hughes JM, Wilcox LS, Tylor LR, Trussell J. The risk of pregnancy after tubal sterilization: Findings from the U.S. collaborative review of sterilization. Am J Obstet Gynecol. 1996;174:1161-8.

9. Vessey M, Huggins G, Lawless M, McPherson K, Yeates D. Tubal sterilization: findings in a large prospective study. $\mathrm{Br}$ J Obstet Gynaecol. 1983;90:203-9.

10. Lassner KJ, Chen CH, Oberle MW, da Trindade TC, Aguinaga $H$. Analysis of sterilization failure in Brazil. Int J Gynaecol Obstet. 1988;27:255-63. 
11. Hughes GJ. Sterilisation failure. $\mathrm{Br}$ Med J. 1977;2:1337-9.

12. Roy KK, Banerjee N, Takkar D. Pregnancy following tubal sterilization: An 11-year survey. Int J Gynaecol Obstet. 2000;68:53-4.

13. Stovall TG, Ling FW, Henry GM, Ryan GM., Jr Method failures of laparoscopic tubal sterilization in a residency training program. A comparison of the tubal ring and spring-loaded clip. J Reprod Med. 1991;36:283-6.

14. Destefano F, Peterson HB, Ectopic pregnancy after sterilization. J Amer Med Assoc. 1984;251:1432.

15. Stock RJ, Nelson KJ, Ectopic pregnancy subsequent to sterilization: hisotologic evaluation and clinical implications. Fertil Steril. 1984;42:211-5.

16. Horuine LH, O'Hara KE, Failed tubal sterilization as an etiologica factor in ectipic tubes pregnancy. Fertil Steril. 1978;29:509-11.

17. Malcova E, Kemp A, Hart R, Jama K. Long-term risk of ectopic pregnancy varies by method of tubal sterilization: a whole -population study. Fertility and Sterility. 2004;101:728-34.

18. Sivanesaratnam V, Ng KH. Tubal pregnancies followitn postpartum sterilization. Fertil Steril. 1975;26:945-6.
19. Chi VC, Inure LE, Altwood RJ. Ectopic pregnancy following -female sterilization procedure. Adv Plann Parent. 1981;16:52.

20. Peterson HB, Xia Z, Hughes JM, Wilcox LS, Trussel J. The risk of pregnancy after tubal sterilization: findings from U.S collaborative review of sterilization. Am J Obstet Gynecol. 1996:174;116270.

21. Menken J, Trussel J, Larsen U. Age and infertility. Science. 1986:;33:1389-94.

22. Stoval TG, Ling FW, O'Kelley KR, Coleman SA. Gross and histologic examination of tubal ligation failure in a residency training program. Obster Gynecol. 1990;76:461-5.

23. Soderstrom RM, Levy BS, Engel T. Reducing bipolar sterilization failures. Obstet Gynecol. 1989;74:60-3.

24. Peterson B. Sterilization. Obstet Gynecol. 2008;111:189-203.

Cite this article as: Sarella LK. Evaluation of post sterilization ectopic gestations.Int J Reprod Contracept Obstet Gynecol 2017;6:1503-6. 